\title{
Reflexiones sobre las nuevas redefiniciones en torno al cuerpo desde la perspectiva de género ${ }^{1}$
}

\author{
Nubia Amparo Rubio Moreno ${ }^{2}$ \\ Universidad Santo Tomás
}

Recibido: 13 de noviembre de 2009 • Aprobado: 3 de mayo de 2010

\section{Resumen}

Partiendo de la premisa de que la existencia es en primer término corporal, el objetivo del artículo se centra en analizar desde distintas miradas la temática del cuerpo. Teniendo en cuenta que lo que el hombre pone en juego en el terreno de lo físico tiene origen en un conjunto de sistemas simbólicos, los cuales tienen lugar en la cultura a la que se pertenece. Dichos símbolos transmiten valores y resignifican la acción social del individuo y de la sociedad en la cual está inmerso. Desde esta nueva perspectiva, aparece la categoría: cuerpo, como motivo de reflexión sociocultural, bajo los parámetros de la transición a la modernidad, en los cuales la transdisciplinariedad y la complejidad se convierten en los avales para que el cuerpo adquiera un nuevo significado, en el que se pueden observar, con nuevas miradas, los procesos sexo-genéricos que se viven en el mundo contemporáneo.

Palabras clave: cuerpo, género, simbólico, sociocultural, naturaleza, cultura.

1 Este artículo pertenece a los resultados de investigación del Grupo Catalina de Siena, inscrito en Colciencias, el cual tiene como línea de investigación las problemáticas de género, identidades y subjetividades contemporáneas.

2 Socióloga. Magíster en Planeación Socioeconómica. Integrante del Grupo Catalina de Siena: Mujer y Género. Docente del Departamento de Humanidades y Formación Integral. Universidad Santo Tomás. Correo electrónico: nubiarubio@usantotomas.edu.co 


\section{Reflections on the new redefinitions around the body from a gender perspective}

\section{Abstract}

Starting from the premise that existence is in first instance in the body, the objective of the article focuses on analyzing the topic from different perspectives of the body. Taking into account that man is at stake in the realm of the physical is rooted in a set of symbolic systems, which take place in the culture to which we belong. These symbols convey values and redefine the social action of the individual and the society in which it is immersed. From this new perspective, appears the category "body" as a reason for a socialcultural thought, under the parameters of the transition to modernity, in which transdisciplinary and complexity become the "collateral" for the body to acquire a new meaning, which can be seen with new eyes, sex generic processes that are experienced in the contemporary world.

Key words: body, gender, symbolic, socio-cultural, nature and culture. 


\section{Réflexion sur les nouvelles redéfinitions autour du corps depuis la perspective de genre}

\section{Résumé}

En partant de la prémisse que l'existence est en premier lieu corporelle, l'objectif de l'article se centre sur l'analyse de la thématique du corps selon différents points de vue, tenant en compte le fait que ce que l'homme met en jeu sur le terrain du physique tire son origine d'un ensemble de systèmes symboliques, qui s'enracinent dans la culture à laquelle il appartient. Ces symboles mentionnés transmettent des valeurs et resignifient l'action sociale de l'individu et de la société dans laquelle il est immergé. Depuis cette nouvelle perspective, la catégorie de "corps" apparaît comme motif de réflexion socioculturelle, sous les paramètres de la transition à la modernité dans lesquels la transdisciplinarité et la complexité se convertissent en "avals" pour que le corps acquière un nouveau signifié, dans lequel on puisse observer, sous de nouveaux regards, les processus sexes genres qui se vivent dans le monde contemporain.

Mots-clé: corps, genre, symbolique, socioculturel, nature, culture. 


\section{Introducción}

Desde mediados del siglo XX, el trabajo académico sobre la problemática femenina ha venido abriendo caminos que hoy nos permiten tener una nueva mirada de lo que técnicamente se ha venido consolidando como la perspectiva de género. Tradicionalmente, los estudios de género han pretendido analizar críticamente las construcciones teóricas patriarcales y, en general, los constructos socioculturales que subyacen en los diferentes análisis sobre dicha temática; se han propuesto extraer, fortalecery consolidar la historia de las voces silenciadas que se han preocupado por defender la igualdad entre los sexos y la emancipación de las mujeres. Es así como se puede afirmar hoy que la teoría feminista ha contribuido con sus aportes a la estructuración y maduración de una nueva forma de interrogar la realidad, de acuñar nuevas categorías analíticas, con el fin de explicar aspectos de la realidad que no habían sido tenidos en cuenta. Sin embargo, la categoría de género parece ser insuficiente para explicar algunas inquietudes de carácter teórico, las cuales han obligado a reflexionar sobre una nueva categoría que no es otra que la del cuerpo.

Si se revisan las diferentes definiciones sociales sobre el cuerpo hay un consenso en asumirlo, no como un hecho físico sino más bien como una elaboración. No es un conjunto de órganos, sino que la percepción cultural de ellos construye un discurso paralelo al orden social y la cosmovisión de cada pueblo. Siendo así, el cuerpo se plantea no como algo indiscernible del ser humano sino como una posesión, un atributo; es al mismo tiempo lo que encarna al ser humano, su marca, su frontera, de alguna manera, el tope que lo distingue de los otros. Según Le Breton (2008b), el ser humano "no es producto de su cuerpo, él mismo produce las cualidades de su cuerpo en su interacción con los otros y en su inmersión en el campo simbólico. La corporeidad se construye socialmente" (p. 19).

\section{Imaginarios sociales y cultura}

Aquello tangible que podría parecernos dado está también imbuido de diferentes elementos sociales, que a su vez regulan el modo en que sentimos, 
experimentamos y actuamos con nuestro cuerpo. El cuerpo está rodeado de imaginarios sociales y de prácticas, hechos sociales y culturales, es decir, hay una relación de ida y venida entre ambos. Como dice Le Breton (2008b), "el cuerpo metaforiza lo social y lo social metaforiza el cuerpo. En el recinto del cuerpo se despliegan simbólicamente desafíos sociales y culturales" ( $p$. 73). Por tanto, no es de extrañar que en esta construcción se reproduzcan diferencias de género, dado que ellas existen en las sociedades en las que vivimos como estructuras esenciales de las identidades y los roles culturalmente asignados.

El cuerpo, moldeado por el contexto social y cultural en el que se sumerge el actor, es ese vector semántico por medio del cual se construye la evidencia de la relación con el mundo, las acciones que tejen la trama de la vida cotidiana, desde las más triviales y de las que menos nos damos cuenta, hasta las que se producen en la escena pública implican la intervención de la corporeidad.

Para el desarrollo de la presente reflexión es necesario tener en cuenta que la existencia es en primer término corporal, razón por la cual el objetivo de la mayoría de las ciencias sociales que se ocupan del tema debería ser el de tratar de comprender las lógicas sociales y culturales que costean el espesor y los movimientos del hombre; haciendo evidente que lo que el hombre pone en juego en el terreno de lo físico se origina en un conjunto de sistemas simbólicos otorgados desde la cultura a la que se pertenece. Del cuerpo nacen y se propagan las significaciones que constituyen la base de la existencia individual y colectiva. En este sentido, el cuerpo es el eje de la relación con el mundo, el lugar y el tiempo en el que la existencia se hace carne a través de la mirada singular de un actor.

\section{El cuerpo como eje de relación con el mundo}

A través del cuerpo, el hombre se apropia de la sustancia de su vida y la traduce en dirección de los demás por intermedio de los sistemas simbólicos que comparte con los otros miembros de la sociedad a la que pertenece. El actor abraza físicamente al mundo y lo hace suyo al humanizarlo y, sobre todo, al convertirlo en un universo familiar y comprensible, cargado de sentidos y de 
valores, compartible en cuanto experiencia por todo actor que esté inserto como él en el mismo sistema de referencias culturales.

En esta perspectiva, existir significa en primer lugar moverse en un espacio y en un tiempo, significa transformar el entorno gracias a una suma de gestos eficaces, lo que permite clasificar y atribuir un valor a los innumerables estímulos del entorno gracias a las actividades perceptivas, las cuales permiten dirigir a los demás palabras, pero también gestos y ademanes, un conjunto de rituales corporales que cuentan con la adhesión de los otros.

A través de su corporeidad, el hombre hace que el mundo sea la medida de su experiencia. Lo transforma en un tejido familiar y coherente, disponible para su acción y permeable a su comprensión. Como emisor o como receptor, el cuerpo produce sentido continuamente y de este modo el hombre se inserta activamente en un espacio social y cultural dado.

Al nacer el niño, por ejemplo, se encuentra con toda una suma infinita de disposiciones antropológicas que solamente la inmersión en el campo del mundo simbólico, es decir, en la relación con los otros, se puede desplegar. Este proceso de socialización de la experiencia corporal es una constante de la condición social del hombre que, sin embargo, tiene sus momentos más fuertes en ciertos períodos de su existencia, especialmente en la infancia y en la adolescencia. El niño nace inmerso en un estrato determinado, el cual le posibilita o le trunca su relación con el mundo de posibilidades, en la medida que ocupa una posición propia en el juego de variaciones que caracterizan la relación con el mundo de la comunidad a la que pertenece.

Los hechos y gestos del niño están rodeados por este "ethos" que provoca las formas de su sensibilidad, de sus movimientos comunicativos, de sus actividades perceptivas $y$, de este modo, dibuja el estilo de su relación con el mundo. La manera en que el niño/a se sitúa en esa trama de la sumisión o la resistencia que oponga, dan lugar a coordenadas que son consideradas cada vez más importantes en los procesos de socialización desde los diferentes contextos culturales. 


\section{Las perspectivas biológica, neurológica y genética}

Sin embargo, existen discursos que pretenden dar cuenta de las lógicas corporales de la condición humana desde otras perspectivas diferentes; por ejemplo, la perspectiva biológica, la neurológica o la genética. Desde estas perspectivas, la corporeidad está subordinada a la naturaleza. Estos trabajos se inscriben en la tradición darwiniana abierta por La expresión de las emociones en los hombres y en los animales (1872). En este sentido, lo que el cuerpo pone en juego, especialmente en sus dimensiones faciales o gestuales, es la traducción física de las emociones del actor, lo cual forma parte de mecanismos biológicos universales e innatos.

\section{La sociobiología}

Por su parte, Wilson (1980) deseaba establecer un estudio sistemático de los fundamentos biológicos de todos los comportamientos sociales:

A la idea de que las significaciones se constituyen en el plano social, resume Marshall Sahlins, se le opone la que sostiene que las interacciones humanas están determinadas en el plano biológico. Desde una perspectiva evolucionista, esto se desprendería esencialmente de una propensión de los genotipos, tomados aisladamente, a maximizar sus posibilidades de reproducción. (p. 66)

Según Wilson (1980), la inteligibilidad de la acción humana no está de ningún modo arraigada en la dinámica del vínculo social y debería ser simplemente buscada en el cerebro del hombre:"Sólo cuando se haya desmontado totalmente el mecanismo sobre su papel en el nivel celular y, luego, reconstruido, propiedades como la emoción y el juicio ético, podrán quedar aclaradas" (p. 66). En sus conclusiones, Wilson corre la cortina de un fantasma político que podría darle pleno poder a los biólogos. A su entender, lo importante es construir "un código ético genéticamente correcto y, por lo tanto, perfectamente igualitario" (p. 66). Sueño todopoderoso que nos deja, al mismo tiempo, soñadores e inquietos. 
Dejar la iniciativa de la ética social a los genes y a los genetistas no parece para nada prudente. Los sociobiólogos y muchos etólogos transfieren sin ningún tipo de corrección los datos recogidos en sus estudios con animales a lo social (R. Ardrey, 1978; D. Morris, 1996; Eibl Eibesfeldt, 1987; K. Lorenz, 1973; etc.) Para ellos, el sistema simbólico de las relaciones entre los actores y el funcionamiento colectivo de las comunidades humanas depende estrechamente de una programación genética, fijada durante la filogénesis y que convierte a la cultura en un simple artefacto de lo biológico. La dimensión simbólica no sería más que el calco en el plano social de un sistema de disposiciones genéticas que se imponen al hombre en todas sus latitudes. Así, los sociobiólogos transplantan un esquema animal al hombre sin interrogarse sobre la diferencia entre estos dos reinos como consecuencia de la mediación cultural introducida por el hombre.

Frente a la complejidad y a la plasticidad de la condición humana, la sociobiología está obligada a privilegiar argumentos de autoridad provenientes de un imaginario biológico. Rechaza la preocupación por observar un hombre real, vivo, en una sociedad determinada, en un momento determinado. De hecho, prefiere el estudio de los mecanismos neurológicos de los comportamientos al de las relaciones del hombre con el mundo. Su predilección son los mecanismos musculares más que los que se producen por la corporeidad humana. Sahlins (1988) escribe:

En el hombre, las mismas motivaciones intervienen en diferentes formas culturales, y las mismas formas hacen intervenir motivaciones diferentes. En ausencia de una concordancia invariable entre el carácter de la sociedad y el carácter humano, no podría existir determinismo biológico (p. 38).

La

\section{presencia de las ciencias sociales}

Si la sociología del cuerpo permanece en el campo epistemológico de las ciencias sociales, no puede hacer otra cosa que oponerse vigorosamente a la sociobiología, que convierte al hombre en un producto de su cuerpo, basado en la naturaleza. Los trabajos de origen sociológico muestran que los productos del cuerpo en la existencia del hombre, lejos de ser artefactos de una organización 
biológica e instintiva, obedecen a una construcción lógica, simbólica, cultural y social. No hay bases instintivas en la conducta humana, algo que experimenta cualquier familia que adopte un niño proveniente de otra sociedad o dos gemelos criados por padres adoptivos de diferentes sociedades los cuales desarrollan conductas de comportamiento totalmente contrarias habiendo sido producto del mismo zigoto y numerosos trabajos etnológicos que describen la extraordinaria variación de las conductas humanas entre sociedades y entre momentos históricos o, también, el caso de los llamados "niños salvajes"o, más sencillamente, las diferencias significativas de relaciones con el mundo de las segundas generaciones, en relación con sus padres inmigrados.

El niño que nace en la selva amazónica, en una maternidad de Estrasburgo o de Tokio dispone de las mismas potencialidades, de las mismas capacidades para aprender. Pero es su inserción en un grupo social sui géneris lo que le otorga ciertas formas específicas que van a determinar su comprensión de sentido de acuerdo con la educación que reciba.

La única universalidad consiste en la facultad de sumergirse en el orden simbólico de una sociedad, ese privilegio de entrar como actor a un mundo de significaciones y de valores que no agota ninguna cultura. La condición humana y, por consiguiente, también, la dimensión física de su relación con el mundo (Le Bretón, 2008b), está subsumida en un universo de sentido que hace cuerpo con ella y que mantiene el vínculo social.

La sociología del cuerpo muestra la importancia de la relación con el otro en el moldeado de la corporeidad. Comprueba con facilidad la influencia de las pertenencias culturales y sociales en la elaboración de la relación con el cuerpo, pero no desconoce la adaptabilidad que a veces permite que el actor se integre a otra sociedad (migraciones, exilios, viajes) y que, de acuerdo con sus maneras de ser y con el correr del tiempo, tiene entonces la oportunidad de asumir otros modelos.

Si la corporeidad es una materia simbólica, no es una fatalidad que el hombre debe asumir y cuyas manifestaciones se despliegan sin que él pueda hacer nada. A la inversa, el cuerpo es objeto de una continua construcción social y cultural. 
En este sentido, se puede afirmar que la temática del cuerpo como reflexión sociocultural se ha llevado a cabo a partir de trabajos transdisciplinarios e interdisciplinarios de las ciencias sociales, los cuales han permitido observar procesos sexo-genéricos que se viven en el mundo contemporáneo. Dichos trabajos han permitido que el cuerpo sea entendido y mirado bajo parámetros que van más allá de la visión biológica y psicológica, pasando a ser visto y reconocido como una construcción social que sintetiza la dialéctica naturaleza-cultura, en la que el cuerpo y sus prácticas conforman un referente significativo de identidad.

\section{Nuevas posibilidades epistemológicas}

En el seno de esta nueva mirada se consideran oportunas las ambigüedades e incertidumbres; no se le tiene temor a la crisis de la ciencia y al surgimiento de nuevas formas de conocimiento; se facilita el diálogo de nuevos métodos de trabajo, se trabaja arduamente en la revisión de teorías previamente establecidas, se tiene muy en cuenta la duda acerca de lo establecido como verdadero, en la medida que facilita la ruptura con la visión naturalista y biológica, que en la tradición académica se le ha dado al cuerpo. Siendo así, la acumulación y el desarrollo de estos procesos científicos basados en la transdisciplinariedad y la complejidad han generado la posibilidad de conocer y trabajar múltiples escenarios disciplinares socioculturales.

\section{Subordinación social femenina}

Una mirada muy importante desde esta transdisciplinariedad la hace Turner (1989) quien recalca la necesidad de tener en cuenta que en cualquier sociología del cuerpo se debe trabajar la división sexual y emocional del trabajo. En este estudio, el análisis del cuerpo se convierte necesariamente en un estudio sociológico del control de la sexualidad femenina, controlado por la cultura del poder patriarcal. Nos dice que hay dos explicaciones a la subordinación social de las mujeres: una de ellas es el argumento naturaleza-cultura; la otra, el argumento de la propiedad. La primera sustenta que, debido a su 
papel reproductivo en las sociedades humanas, las mujeres están más asociadas con la naturaleza que con la cultura y de ahí que tengan un estatus presocial o subsocial, lo que significa que las mujeres con estos estatus no han superado su estadio de animalidad, ya que se encuentran atadas a la naturaleza en virtud de su sexualidad y fertilidad. En este orden de ideas, la subordinación de las mujeres no es en esencia producto de la fisiología, sino de la interpretación cultural de la reproductividad femenina, como algo que denota un vínculo irrompible con la naturaleza, en esta división del trabajo. Los hombres crean símbolos durables, mientras que las mujeres reproducen cuerpos perecederos. Desde esta perspectiva del autor, los roles de las mujeres, como consecuencia, llegan a ser vistos como inferiores a los roles sociales desempeñados por los hombres $y$, desde esta mirada, se relaciona lo femenino con lo psíquico: instintos maternales, afectividad, emociones, etc., y a los hombres, con la razón, la confiabilidad, etc. Esta mirada también ubica a lo femenino en el ámbito privado y al hombre, en el público.

Luego, Turner (1989) nos expone las dificultades de este análisis diciéndonos que, en las sociedades premodernas, el patriarcado implica de forma típica el ejercicio del poder por los varones adultos sobre las mujeres, los niños y otros hombres dependientes y que es difícil separar el patriarcado de la gerontocracia, esto es, el predominio político de los hombres ancianos sobre los miembros de todas las generaciones y sexo. Una solución para el argumento sería sostener que los hombres dependientes, junto con las mujeres, son identificados con la naturaleza, como era el caso de los jóvenes que no eran primogénitos y no tenían a sus espaldas el peso de mantener la propiedad y la familia en el feudalismo.

Una segunda debilidad del argumento que sostiene que las mujeres pertenecen al plano de lo biológico, justificado desde la capacidad de procrear, según Turner (1989), sería su generalidad. Aristóteles, por ejemplo, consideraba a las mujeres como desviaciones en la naturaleza. En el Medioevo, es específicamente negado que la mujer tenga algún papel activo en la reproducción de hombres; es la simiente masculina la única fecunda. Si no se pensaba que las mujeres eran relevantes en la reproducción, ¿cómo podía pensarse que estuvieran próximas a la naturaleza? 
La tercera debilidad, según Turner (1989), es la continuidad del argumento naturaleza/cultura, la cual se vuelve cada vez más imprecisa en las sociedades caracterizadas por la urbanización, la secularización y la medicina científica, tales como los avances en tecnología genética: ovogénesis, bancos de esperma, inseminación artificial, bebes de diseño, microcirugía embrionaria, transgénicos $y$, en general, la pluridimencionalidad desde el descubrimiento del genoma humano, lo que de hecho y de forma muy evidente significa que la cultura interviene de forma masiva en los procesos naturales; en este caso específico, lo que se consideraba como "reproducción natural se hace cada vez más incierto y lo que considerábamos por completo del reino de la naturaleza puede pasar por completo al reino de la cultura" (p.152).

\section{La herencia académica de la problemática de género}

En este punto de la discusión vale la pena tener en cuenta que uno de los más grandes aportes del feminismo a la teoría contemporánea ha sido el concepto de género, por medio del cual se establece que lo masculino y lo femenino son construcciones psicosociales, lo que significa que los roles de hombres y mujeres, en primer lugar, son diferentes, y en segundo lugar, que vienen determinados por factores culturales y sociales asignados a los géneros y no por hechos naturales o biológicos.

Siendo así, el concepto de género es caracterizado como una construcción cultural frente al concepto de sexo. En este sentido, el sexo se ha vinculado a la biología y a la naturaleza y el género, a la cultura y a la sociedad. Teniendo esto en cuenta, podemos hablar de que "la identidad humana está compuesta por el sexo biológico, el género, la identidad sexual y la orientación sexual" (Amoros, 1995, p. 60).

\section{La presencia de la genética y la construcción sociocultural}

Por supuesto que alrededor de esta postura se dan muchas discusiones, por ejemplo, en una noticia aparecida el 21 de octubre de 2003, en el diario El País, 
de España, se afirmaba que la identidad sexual podía explicarse a través de los genes. Independientemente de que esto sea cierto o no, lo más importante es la influencia de los aspectos sociales y culturales; además, incluso, aunque se admitiera que la existencia de los genes explican la identidad sexual, no tendríamos que olvidarnos que sobre esa identidad no se debe ejercer ninguna imposición; el género es el que determina las construcciones culturales, los roles y papeles asignados a machos y a hembras, independientemente de su identidad o su orientación sexual.

Lo que es importante y que se debe tener en cuenta es que el género está construido sobre el sexo biológico, en el que a los machos y a las hembras se les asignan unas características que son construcciones sociales y culturales que hacen que éstas/os sean representadas/os de distintas maneras: los hombres simbolizan la dominación y las mujeres, la sumisión; ello hace que se establezcan estereotipos sobre hombres y mujeres, razón por la cual a la mujer se le describe siempre como delicada, sensible, tierna, femenina, predispuesta a la chismosería, y, por supuesto, siempre alejada de todos aquellos roles que le son asignados a los machos. Cuando se da la transgresión del rol, ésta es fustigada de manera inmediata por la sociedad con expresiones tales como "marimacha" o términos similares, según la generación, que se encargan de señalar de manera inmediata que no se está adaptando al rol previamente establecido por la sociedad y la cultura; de hecho, este no es el caso exclusivo de las mujeres; en el caso de los hombres ocurre exactamente lo mismo: la construcción sociocultural no puede pasar inadvertida porque el varón que desconozca la regla de inmediato queda incluido en la categoría de "mariquita", de llorón, de sentimentalista, de falto de virilidad o cualquier otro adjetivo que sirva para remarcar que abandonó una posición que estaba muy bien definida desde la intencionalidad social para lo masculino: la de proveedor económico y, por supuesto, previamente establecida desde su procesos de socialización.

\section{Sexo, género e identidad sexual}

En este contexto, el sexo biológico sería la parte invariable: nacemos siendo machos o hembras, pero también hermafroditas. El género es la construcción 
psicosocial y tanto machos como hembras se pueden sentir femeninas o masculinos (otro aspecto es la presión social que se hace para que los machos "sean masculinos" y las hembras, "femeninas", con sus "correspondientes roles"). En último lugar, está la identidad sexual, que es independiente de la orientación sexual que se elija en la elección erótica-afectiva-sexual, que en todos los casos puede ser homosexual, bisexual, lésbica, transgénero o heterosexual, es decir, por medio del proceso de socialización, más específicamente en el adiestramiento de roles sexuales, se desarrolla una identidad sexual acorde con el sexo biológico, pero esto no implica que a nivel de orientación sexual se elija lo esperado por una sociedad o sea una orientación sexual heterosexual.

Por otra parte, el hombre tiene la facultad de fecundar a la mujer, en tanto que ésta tiene regularmente menstruaciones, engendra hijos, los pare y luego les da de mamar; estos son los rasgos estructurales en torno de los cuales las sociedades humanas trabajan siempre para definir socialmente lo que es característico del hombre y lo que le corresponde a la mujer, las cualidades y estatus respectivos que echan raíces en su relación con el mundo y entre ellos.

\section{Imaginarios sociales y diferencias culturales}

Que el cuerpo no sea el marcador fatal de una pertenencia biológica queda demostrado por el ejemplo de los Nuer, para los que únicamente las mujeres que tienen hijos pueden ser realmente consideradas mujeres. La mujer estéril es vista como un hombre. A su vez, el hombre puede tener una o varias esposas si tiene medios para pagar sus dotes. Sus mujeres pueden ser fecundadas por parientes o amigos o, incluso, por un hombre de una tribu subordinada a los Nuer, los Dinka. Este hombre no es el progenitor del hijo: la mujer es su padre y tiene todas las prerrogativas sociales de esta función.

Un recorrido por el espacio etnológico permitiría multiplicar los ejemplos. Margarete Mead, en Sexo y temperamento en tres sociedades primitivas (1935), mostró el relativismo cultural del estatus de los sexos y de las cualidades que se les atribuye. A través de una investigación con tres sociedades de Nueva Guinea, intenta discernir "la parte de las construcciones mentales en rela- 
ción con la realidad de los hechos biológicos sexuales" (1979, p. 16). En los Arapesch y los Mundugumor, aunque los hombres y las mujeres tienen roles diferentes, no se percibe entre ellos ninguna diferencia de temperamento. Mead (1979) nos cuenta:

No existen ideas del orden de la dominación, el coraje, la agresividad, la objetividad, la maleabilidad, que puedan asociarse a un sexo en oposición al otro... Los Chambuli, por el contrario, nos dieron una imagen inversa de lo que sucede en nuestra sociedad. La mujer es la dominante, tiene la cabeza fría y es la que conduce el bote; de los dos, el hombre es el menos capaz y el más emotivo. (p. 17)

Las características físicas y morales, los atributos asignados al sexo, provienen de elecciones culturales y sociales y no de una inclinación natural que establecería de una vez y para siempre al hombre y a la mujer en un destino biológico. La condición del hombre y de la mujer no está inscrita en su estado corporal, está socialmente construida. Como decía Simone de Beauvoir:"No se nace mujer, se llega a serlo". Y lo mismo sucede con el hombre.

Es en este sentido que la presencia del concepto de género ha permitido comprender que la libertad con la que nace el ser humano se va restringiendo a lo largo de su historia. Los seres humanos dependen de las situaciones que se van dando en su entorno, que lo van construyendo social y culturalmente, haciendo que hombres y mujeres desempeñen papeles diferentes en su contexto, en una situación de desigualdad, previa y plenamente determinada por el sistema sexo-genérico, en el que la marginación de la mujer se comprende en nuestras sociedades como un fenómeno natural, en el cual las construcciones que se proyectan sobre hombres y mujeres hacen que los individuos de un mismo sexo se homogenicen y se asignen cuotas bastante desiguales en cuanto a la distribución del poder (mucho menor en la mujeres, por supuesto). 


\section{Más allá de la problemática sexo-genérica}

De esta forma se puede concluir que el cuerpo vuelve a ocupar un lugar primordial como categoría que permite el análisis de las problemáticas sexogenéricas que se presentan en la actualidad.

Lo que se puede observar es que siguiendo una mirada feminista, la dicotomía sexo/género se convirtió en una lucha política que repudiaba la subordinación de la mujer. En este sentido, el sexo estaba determinado por factores biológicos y, a su vez, el género estaba determinado por factores sociales y culturales. Pero esta cruzada se centró, sobre todo, en realzar la categoría del género y, por el contrario, dejó intacta e incuestionable la categoría del sexo. Partiendo del presupuesto de que la biología o el sexo son categorías fijas, las feministas tendieron a hacer hincapié en las transformaciones a nivel del género. Su proyecto fue, de alguna manera, minimizar las diferencias biológicas y proveerles diferentes significados y valores culturales. Como se observa, la premisa "la biología es destino" era totalmente cuestionada por estas feministas para confrontar la asimetría existente entre hombres y mujeres.

El paso siguiente ha sido el de reconocer la aparición de una nueva dimensión del concepto de cuerpo como fruto de las discusiones de los años 80 , en los cuales la distinción sexo/género fue ampliamente criticada por diferentes autores, provenientes de distintas corrientes teóricas. Lo que se cuestiona es la consideración de lo biológico (el sexo) como una superficie pasiva y vacía que únicamente se tuvo en cuenta como un elemento que brinda el soporte necesario para que lo sociocultural (el género) le otorgue forma. Es imperativo que se llegue a la conclusión de que lo biológico es en sí una construcción cultural. Ya no se puede seguir considerando al cuerpo, y por lo tanto al sexo, como aculturales y prelingüísticos.

\section{La opresión sexista en la herencia patriarcal}

Lo que se ha tratado de consolidar es la lectura de un cuerpo que represente los significados de las metáforas sociales. Recordemos que desde una óptica 
estructuralista, Michel Foucault considera al cuerpo como un texto donde se pueden leer las relaciones de poder que se han inscrito sobre él. En una de sus obras más relevantes, Vigilary Castigar (1989), analiza la desaparición del castigo como espectáculo público de violencia en contra del cuerpo y el surgimiento de la prisión como una nueva forma general de castigo moderno basado en el disciplinamiento corporal. Se centra, sobre todo, en el análisis del sistema discursivo y de los dispositivos de poder en torno al cuerpo. Puntualmente, utiliza el término "tecnología" para referirse a los procesos de conexión entre las prácticas discursivas, las relaciones institucionales y los efectos materiales que, actuando conjuntamente, producen afirmaciones "verdaderas" sobre los cuerpos.

Las expectativas que se crean sobre los sexos son diferentes desde el nacimiento, pero además las sociedades a las que pertenecemos están basadas en sistemas altamente jerarquizados en los que la regulación de las prohibiciones está perfectamente definida; es absolutamente claro que en esta jerarquía las mujeres siempre tienen menor valor. Hombres y mujeres a lo largo de la historia han desempeñado diferentes roles; estos roles han sido asignados a los sexos de una forma jerárquica patriarcal, en la que los hombres siempre han tenido una posición superior en la estructura social; esto ha ocurrido en todas las sociedades, la verdad es que hasta el momento no se conoce ninguna sociedad que haya sido real y estrictamente matriarcal.

La base de la opresión sexista se encuentra en la estructura de las instituciones consolidadas en la herencia patriarcal, en donde las mujeres no tienen un proyecto de vida propio, pues se les ha enseñado a través del amor a vivir para servir a los otros. Los papeles de género han sido impuestos por la estructura familiar y por las instituciones sociales como: las leyes, la familia, la iglesia, la escuela, etc. Al ser así, la diferencia y la desigualdad se van marcando, de acuerdo con la manera como se les asigne a la "niña-mujer" y al "niño-hombre" sus roles respectivos desde su estructura social.

A la niña se le asociará siempre con la naturaleza, el cuerpo y la biología, y al niño, con la razón y la fuerza, teniendo como consecuencia que muchas de las conclusiones van a ser expresadas de alguna manera en la violencia de género ampliada más adelante. Para una mejor comprensión es necesario 
entender que el modelo sexual de Occidente se erige sobre la base de unas premisas presentadas como naturales e incuestionables: existen sólo dos sexos; a un cuerpo de macho le corresponde una identidad como varón y a un cuerpo de hembra, una identidad como mujer, y desde este esquema preconcebido se erigen ecuaciones tales como: mujer-madre-cuidadora y reproductora (esfera privada); hombre proveedor económico (esfera pública). Sin embargo, este sistema dicotómico se ha encontrado con enormes fisuras que han permitido formular nuevos interrogantes que escapan de la ecuación que se pretende natural y que ha permitido repensar la realidad de los sexos y los géneros en el mundo contemporáneo.

\section{El cuerpo, fenómeno sociocultural e histórico}

Los diferentes recorridos realizados desde las instituciones académicas, desde el mundo intelectual y político, de los diferentes aportes en torno a la dicotomía sexo/género, han permitido que se cuestionen categorías y estructuras de todo el ordenamiento sexual occidental, vinculado a una cultura falocéntrica o a los mecanismos de poder de la norma heterosexual. Sin embargo, estas críticas están acompañadas, como se observa, de una clara tendencia a la descorporeización de las identidades. Para precisar aún más, se pretende abandonar la idea de un cuerpo sexuado que determina la forma de actuar de los géneros, de modo tal que las construcciones socioculturales a partir de las cuales se pretende explicar la problemática de género están olvidando una de las partes más importantes de la discusión: el cuerpo. Esta es la razón por la cual, en las últimas décadas, el cuerpo ha ido ocupando una posición destacada dentro de la teoría social. Una buena parte de los teóricos se han distanciado de la concepción de un cuerpo biológicamente dado para redefinirlo como un fenómeno sociocultural e histórico (Bourdieu, 1977; Foucault, 1989; Goffman, 2006; Mauss, 1979; entre otros).

\section{El cuerpo femenino}

De hecho, la mujer ha sido constantemente sujeto de explotación y opresión a través de la utilización de su cuerpo para los fines de la reproducción, 
haciendo de su función biológica una opresión social, contradiciendo de manera directa los fundamentos de la modernidad, los cuales reconocen que el uso de la razón es necesario y fundamental para que toda persona pueda constituirse en sujeto de derechos libre e independiente. Es muy importante considerar que una consecuencia de no asociar a la mujer con la razón y sí con el cuerpo sería el considerar a la mujer como pre-moderna, como preindividuo, de manera que no se contempla con derechos individuales propios sino sólo englobada en y desde los derechos del hombre, lo que se conoce en las diferentes literaturas como el androcentrismo y lo que nos reafirman constantemente los medios masivos de comunicación desde la publicidad, por ejemplo; aspecto investigado ampliamente por el sociólogo Goffman (1988), donde se ponen en escena a hombres y mujeres que evocan más o menos abiertamente la división y la jerarquía tradicional de los sexos.

Así, la mujer suele estar en una posición subalterna o asistida, en tanto que el hombre, más alto, más fornido, la cuida con una actitud protectora que incluye tanto la esfera profesional, como la familiar y la amorosa, o sea, el plano público y el privado. La relación de la mujer con los objetos parece obedecer a un movimiento de caricia, toca con mucha suavidad su frasco de perfume o la chaqueta de su marido. Pero la mujer también puede retirarse simbólicamente de la interacción y remitirse al hombre en cuanto la conducta necesaria: baja los ojos, junta las manos, se coloca detrás del cuerpo del hombre o cubre su cara con una mano suave. Los movimientos del cuerpo también están ritualizados, por ejemplo, una rodilla ligeramente doblada, la cabeza baja, una sonrisa, etc., son maneras de marcar simbólicamente una tierna sumisión frente al hombre, cuya presencia se sugiere alusivamente. Cubrir la cara sonriente o felizmente sorprendida con una mano delicada es un gesto que agrega seducción mientras, al mismo tiempo, se simula una protección frágil de uno mismo cuando se siente desbordado por la emoción. Entre las manos del hombre, la mujer puede ser ritualmente dócil y amorosa: el hombre alimenta a la mujer que tiende ávidamente la boca ante el alimento, ella es su hijo caprichoso y su juguete. A través de este magistral estudio, ilustrado con imágenes precisas, Goffman (1988) muestra que:"la fotografía publicitaria constituye una ritualización de ideales sociales, de manera tal que se corta, se suprime todo lo que impide que el ideal se 
manifieste" (p. 71). Purificar el mundo de su complejidad para erigir frente a lo "eterno femenino" y un hombre "protector y viril", según los estereotipos ampliamente compartidos, constituye la tarea de los publicistas.

Vartabedian (2007) analiza las principales orientaciones teóricas que existen en torno al cuerpo, señalando el cuerpo como expresión simbólica y el cuerpo como agente. En dicho artículo la autora se pregunta por qué en general en las ciencias sociales se sospecha sobre cualquier tipo de consideración especial hacia el cuerpo material, indagando en los principales aportes teóricos provenientes del feminismo en torno a la dicotomía sexo/género y caracteriza el debate entre esencialistas y constructivistas. En un último aparte describe las prácticas corporales llevadas a cabo por las mujeres transexuales para comprender cómo el cuerpo obtiene un espacio fundamental en la construcción de las identidades de género.

\section{El cuerpo simbólico y el cuerpo agente}

En otro sentido, Vartabedian (2007) explica que, siguiendo a Reischer y Koo (2004), se pueden estructurar dos importantes orientaciones teóricas alrededor del cuerpo y de su relación con la sociedad. Por una parte, el cuerpo simbólico, el cual reúne a todos aquellos teóricos que se centran en la naturaleza simbólica o representacional del cuerpo en tanto elemento portador de significado social. En otro sentido, la autora mediante la consideración del cuerpo agente, subraya el rol del cuerpo como un participante activo o agente en el mundo social.

Dentro de la primera perspectiva teórica, la del cuerpo simbólico, Douglas (1973) fue una de las primeras investigadoras en articular el significado simbólico del cuerpo. En sus estudios, el cuerpo humano es una importante fuente de metáforas sobre la organización/desorganización de la sociedad. Considera que las categorizaciones que rodean y definen al cuerpo deben tener un origen social. Para ella, toda expresión natural está determinada por la cultura, es decir, no se puede interpretar al cuerpo sin tener en cuenta la interacción entre la materialidad y las construcciones simbólicas que lo llenan de significado. 
En términos generales, con el significado simbólico se pretende tener una comprensión del cuerpo como un texto que puede ser leído, como un símbolo del mundo social en el cual habita. Aunque esta noción del cuerpo como un reflejo de la sociedad ha sido criticada por aportes que complejizan su estudio no se puede negar la enorme importancia que esta perspectiva representacional ha tenido y tiene en los estudios teóricos del cuerpo.

En la segunda perspectiva teórica, se destaca que el cuerpo también tiene la capacidad de participar activamente en la creación de significados sociales, es decir, es un agente del mundo social. Según Merleau-Ponty (1975), percibimos el mundo con nuestro cuerpo, es decir, "el cuerpo es el vehículo del ser-del-mundo, y poseer un cuerpo es para un viviente conectar con un medio definido, confundirse con ciertos proyectos y comprometerse continuamente con ellos" (p. 100).

En términos generales, lo que quiere significar dicha corriente es que el cuerpo no puede ser más entendido como un hecho de la naturaleza, como un objeto que desafía a la cultura. Por el contrario, el cuerpo es un agente activo de la cultura, tiene una base existencial y está involucrado tanto en la percepción como en la práctica. A través del concepto de embodiment (personificación femenina) se pretende desafiar una concepción pasiva del cuerpo para reconocer, por el contrario, la condición existencial de la vida cultural. Precisando aún más mediante este concepto, se intenta comprender el proceso por el cual cada uno/a de nosotros/as corporeizamos o incorporamos las experiencias y percepciones de nuestro estar-en-el-mundo. Pero esta experiencia corporal vivida no puede ser desligada de la práctica social, es decir, debemos entender que el cuerpo también actúa en el mundo.

Como conclusión de estas dos formas de interpretar el cuerpo, Vartabedian (citada por Reischer y Koo, 2004) concluye:

Estos dos puntos de vista teóricos sobre el cuerpo (como "artefacto" simbólico y como "agente") son, en realidad, complementarios. "Ya que los significados culturales y los valores residen en y sobre el cuerpo material, el cuerpo no sólo refleja estas construcciones sino que también tiene la capacidad de desafiarlos. El cuerpo, por lo tanto, sirve como un vehículo para la acción social incluso cuando significa las realidades sociales" (p. 315). 


\section{El cuerpo como ente real}

Siguiendo algunos análisis con respecto a ciertas miradas del cuerpo, Turner (1989) advierte que hay una clara antipatía en la teoría social contemporánea hacia la carne y todo lo vinculado con ella; señala que hay que considerar los aspectos tanto fisiológicos como sociales del cuerpo, como una relación entre los cuerpos. Una de las observaciones más interesantes es aquella que afirma que resulta curioso destacar que el cuerpo en su materialidad más carnal está ausente, en la mayoría de los estudios que resaltan tanto los aspectos socioculturales de su construcción como los que describen su capacidad de ser un agente en el mundo social. ¿Dónde está el cuerpo que sufre, goza, transpira, engorda o envejece?, ¿dónde el cuerpo minusválido?

Klein (1996) critica específicamente los análisis posmodernistas que convierten al cuerpo en un objeto exterior a uno mismo, son cuerpos que no respiran, no ríen y, según la autora, no tienen corazón: el cuerpo real y carnal está ausente. Lo cierto es que por más que se intente, no se puede negar la materialidad de los cuerpos. Existe la necesidad de hablar sobre el cuerpo material en el pensamiento feminista. Existen hormonas, úteros, próstatas, genes, entre otras partes del cuerpo, que son indispensables para diferenciar al macho de la hembra y que intervienen directamente en las diferentes miradas socioculturales que permiten la interpretación de las múltiples problemáticas que se tienen que afrontar.

Si bien es cierto que en la sociedad actual la mayoría de las mujeres están lejos de permanecer recluidas en la domesticidad y su participación en el trabajo asalariado y la vida pública gozan de un reconocimiento progresivo, la asociación imaginaria mujer-domesticidad sigue siendo eficaz para construir la disminuida autopercepción de una buena parte de las mujeres, quienes no advierten esta situación. Por otra parte y según los análisis, en buena medida, esto implica la poca atención que las ciencias sociales han prestado al espacio doméstico, en particular, por parte de la Sociología. Según García (2004), esto también explica la exclusión efectiva de las mujeres de la categoría de individuo, llevada a cabo por el pensamiento occidental, lo que de hecho ha contribuido a la invisibilidad para el análisis social tanto de las mujeres como de sus quehaceres y sus espacios. 


\section{La democracia como ejercicio de dominación}

Por otra parte, en el mundo contemporáneo se afirma que vivimos bajo un sistema jerárquico patriarcal democrático. Usando el concepto de democracia se ha llevado a pensar, tanto a hombres como a mujeres, que no existen desigualdades; se pretende que en un sistema democrático nos podemos construir como queremos.

Sin embargo, para alcanzar este objetivo tan loable, no se tiene en cuenta la división social del trabajo, la desigualdad en la educación, en el ámbito doméstico, en la vida profesional, en los pocos cargos políticos representados por cuerpos femeninos, etc. La verdad es que lo que reina es la desigualdad y dicha desigualdad se cubre con un manto político que procura hacernos ver que todos somos iguales $y$, por supuesto, indiferenciados, lo cual genera toda una serie de falsas explicaciones en cuanto a la comprensión de las múltiples problemáticas que nos inquieren.

El patriarcado democrático encubierto con la idea de la igualdad implica que muchas mujeres consideren que sus decisiones son tomadas en el pleno ejercicio de la libertad. Sin embargo, es necesario reconocer que existe una fuerte presión social desde este sistema que hace que mujeres y hombres al seguir reproduciendo roles, mantengan las desigualdades y que, en el caso de las mujeres, les sea negada la posibilidad de ser ciudadanas de derechos. Valga como ejemplo que algunas mujeres cobran menos que los hombres en el desempeño de un mismo trabajo. El hecho de que las mujeres hayan accedido al mundo laboral, por supuesto que es un gran paso, pero debe tenerse en cuenta que la mayoría realizan trabajos asignados socialmente a las mujeres (servicios) y que además siguen siendo ellas las encargadas del trabajo doméstico o reproductivo, incluso en los casos en que ocupan cargos de gran responsabilidad, pero sobre todo roles en iguales condiciones que los hombres, en los cuales de hecho impera la explotación y la desigualdad. 


\section{La violencia familiar}

Esta idea permite que nos adentremos momentáneamente en el caso específico de la violencia familiar, explicada desde el sistema patriarcal, en el que algunos hombres consideran que ellos tienen el poder. En su sentir afirman que la mujer tiene que estar sometida a sus decisiones, aún trabajando y aportando económicamente; por ello, entre otras muchas causas, están autorizados para ejercer la violencia, tanto física como psicológica, sobre la mujer, acabando con cualquier posibilidad de igualdad planteada desde perspectivas democráticas.

Para su explicación de la violencia de género, Plaza (2007), investigadora de la Universidad de Valencia, parte de unas imágenes dramáticas de un trabajo previamente realizado por Ana Mendieta, que convocan directamente a una reflexión sobre dicha problemática. La autora afirma que la primera idea que se nos viene a la cabeza cuando se habla de violencia contra las mujeres es la de la violencia física, ejercida directamente sobre el cuerpo de una mujer que se supone que es blanca y de clase media. Pero afortunadamente la autora no se queda allí, sino que profundiza a partir de los siguientes interrogantes: ¿qué es lo que produce este tipo de violencia física directa?, ¿qué es lo que la hace posible?, ¿qué es lo que la permite?, ¿no será que debemos pensar en un concepto de violencia mucho más complejo y sutil?

Afirma Plaza (2007) que la violencia de género no se reduce a la violencia física directa, sino que es una violencia que se ha incubado previamente en toda una violencia simbólica. Se afirma que cuando las mujeres aplicamos a cualquier realidad esquemas mentales $y$, en especial, cuando los aplicamos a las relaciones de poder en las que estamos atrapadas, caemos en la terrible trampa de que dichos esquemas son el producto de la asimilación directa de esas mismas relaciones de poder, razón por la cual en ciertos sentidos nuestro conocimiento crea de alguna manera la violencia simbólica que nosotras mismas sufrimos. Plaza (2007) señala que el dominado no tiene a su disposición elementos que le permitan imaginarse a sí mismo en sus relaciones con el dominador; los instrumentos de que dispone son fruto del pensamiento único del dominador y los comparte con el mismo, razón por 
la cual las categorías construidas siempre estarán inclinadas hacia el punto de vista de los dominadores. Dicho de otro modo, los esquemas que pone en práctica el dominado para percibirse o para percibir a los dominadores (en este caso específico, la mujer) son producto de la asimilación de las clasificaciones que se pretenden naturalizadas, de las que su propio ser es el producto. De esa manera es que, como parte de un proceso que parece natural, se va consolidando la fuerza simbólica que es una violencia que se ejerce de una manera suave, invisible e insidiosa en lo más profundo de los cuerpos.

\section{Conclusiones}

Las sociedades humanas inician el presente milenio afrontando cambios muy rápidos, procesos globales que afectan todas las regiones y los grupos humanos. Las fronteras políticas sufren todo tipo de modificaciones, la derecha se fortalece en algunos de los principales centros de poder a lo largo del planeta, se pueden identificar grandes núcleos de desplazamiento forzado, se pueden reconocer graves alteraciones del medio ambiente, se sufren enormes grados de incertidumbre por los cambios que pueden generar las crisis económicas que ya no son locales y nacionales sino completamente globales. En este contexto, los cambios de la sociedad y la cultura ocupan un lugar central.

Uno de los elementos más universales del cambio sociocultural ha sido el progresivo reconocimiento del papel que las mujeres desempeñan en estos procesos, partiendo de la desigualdad existente en todas las sociedades entre hombres y mujeres; y dentro de estos procesos, encontramos la discusión sexo-genérica en todas su dimensiones, ofreciendo nuevas miradas que nos permiten reformular las formas convencionales como se ha interpretado y redefinido la temática sobre lo femenino y, fundamentalmente, sobre el cuerpo femenino.

La teoría contemporánea de género tiene una gran argumentación y elementos de juicio necesarios y suficientes para analizar los problemas fuera del terreno biológico, y comprende la diferencia entre los géneros a partir 
del terreno simbólico. Pone en cuestión los postulados sobre el origen de la subordinación femenina, dando cuenta de los mecanismos de ésta, tales como la dicotomía naturaleza-cultura, y permite delimitar con claridad y rigor cómo las diferencias entran en una dimensión de desigualdad, juego de poderes y contrapoderes. La perspectiva de género, como nueva manera de interpretación, marca la diferencia entre pensar al cuerpo como objeto y pensar al cuerpo como cuerpo vivido. Así, Merleau-Ponty (1975a) habla del cuerpo vivido desde la perspectiva abierta por su concepción fundamental de la percepción. Es por ésta que se nos revela el cuerpo y por ello nos es imposible decir que únicamente estamos en el mundo; más bien tenemos que decir que el mundo está en nosotros. Esta perspectiva deja afuera la idea del cuerpo como objeto, como algo positivo, duro, indeformable y, por lo mismo, intemporal y extraño a la experiencia que de él tenemos; desarrolla una mirada más atenta de la condición femenina en la cultura patriarcal.

Vemos que la delimitación de la esfera psicosocial mujeres/hombres no está determinada en dicha perspectiva genéticamente, ni se adquiere con rapidez o fácilmente; se construye progresivamente. La categoría de género resulta indispensable para desentrañar los significados de la cultura, para cuestionar códigos heredados, sean éticos, políticos o de cualquier otra índole. Insistiendo en la diferencia, la teoría de género nos ha ayudado a entender que las relaciones de género son una dimensión fundamental para la comprensión del cuerpo femenino como cuerpo vivido. Al hacer un análisis de los niveles psicológicos, culturales, económicos, políticos, la teoría de género ha señalado que las mujeres tienen una forma propia de vivir su cuerpo que es diferente a la de los hombres e ignorada por estos. Las ciencias humanas, aunque han enriquecido la comprensión del ser humano, no nos han proporcionado todavía una visión totalizadora del ente humano; nos hablan únicamente de una acción donde se combinan condiciones del tipo psicológico, social e histórico, sin explorar por ejemplo la subjetividad.

Dentro de esta temática, de lo que se trata es de encontrar una visión holística y dinámica que relacione la naturaleza de la sexualidad con la sociedad y la cultura desde una mirada de género; es necesario reconocer que existe una materialidad y una solidez corporal que de ninguna manera se pueden obviar. 
El objetivo es trascender la odiosa idea de una dualidad única y cerrada, con el fin de alcanzar la construcción de un modelo completo que entienda y articule la materialidad con las construcciones sociales culturales e históricas. Es importante entender al cuerpo como un sistema que produce y, a la vez, es producido por significados sociales.

El recorrido intelectual y político de estos diferentes aportes en torno a la dicotomía sexo/género ha permitido que se cuestionen categorías y estructuras de un ordenamiento sexual occidental vinculado a una cultura falocéntrica o a los mecanismos de poder de la norma heterosexual. Este debe ser un ejercicio permanente de los seres humanos si no queremos caer en las falacias de la dualidad única, de la falsación de las verdaderas ideas democráticas, de la realidad, de la equidad de género, es decir, de todas aquellas necesidades que nos aquejan hoy y que debemos solucionar de la manera más eficaz posible, si realmente queremos encontrar caminos conducentes al desarrollo de estándares humanos que nos permitan hablar de igualdad contemplando la diferencia.

Sin embargo, debe quedar claro que este no es un discurso vacío, sino todo lo contrario, estas críticas están acompañadas de todo un ejército de detractores que pretenden una negación del pensamiento y del cambio generador de desarrollo. No podemos dejarnos avasallar por un discurso patriarcal consolidado a lo largo de los siglos, el cual nos ha tenido marginadas a lo largo de la historia. Todo lo contrario, una verdadera comprensión de nuestro cuerpo y de nuestra realidad sociocultural es la que nos permitirá alcanzar la utopía de un mundo libre en el que quepamos todas/os.

\section{Referencias}

Amoros, C. (1995). Diez palabras clave sobre mujer. Navarra, España: Verbo Divino.

Beauvoir, S. de. (1998). El segundo sexo (Vol. 1 y 2). Madrid, España: Cátedra.

Bento, B. (2003). ¿Quiénes son los/as verdaderos/as transexuales? Memorias del XVI Congreso Mundial de Sexología, La Habana, Cuba, 1-24. 
Berman, M. (1993). Cuerpo y espíritu. La historia oculta de Occidente. Chile: Cuatro Vientos.

Bourdieu, P. (1977). Esbozo de una teoría de la práctica. Cambridge: Cambridge University Press.

Bourdieu, P. (1986). Notas provisionales sobre la percepción social del cuerpo. En C. M. Wright, Materiales de sociología crítica (pp. 183-194). Madrid, España: La Piqueta.

Bourdieu, P. (1997). Hexis corporal. La teoría del mundo social. Barcelona, España: Siglo XXI.

Butler, J. (2001). El género en disputa. El feminismo y la subversión de la identidad. México: Paidós.

Butler, J. (2002). Cuerpos que importan. Sobre los límites materiales y discursivos del 'sexo'. Buenos Aires, Argentina: Paidós.

Comaroff, J. (1985). Órgano del poder, espíritu de resistencia. Chicago, EE. UU.: Chicago University Press.

Csordas, T. (Ed.). (2001). Embodiment y experience. The existential ground of cultura and self. Cambridge, UK: Cambridge University Press.

Diario El País (2003, 21 de octubre).

Douglas, M. (1973). Pureza y peligro. Un análisis de los conceptos de contaminación y tabú. Madrid, España: Siglo XXI.

Fausto-Sterling, A. (2006). Cuerpos sexuados. La política de género y la construcción de la sexualidad. Barcelona, España: Melusina.

Fernández, J. (2004). Cuerpos desobedientes: travestismo e identidad de género. Buenos Aires, Argentina: Edhasa.

Foucault, M. (1989). Vigilar y castigar. Nacimiento de la prisión. Buenos Aires, Argentina: Siglo XXI. 
García, I. (2004, febrero). ¿Cómo se ven las mujeres en Televisión? Razón y Palabra. Primera Revista Digital en Iberoamérica Especializada en Comunicología, (37). Recuperado de www.razonypalabra.org.mx.

Gilman, S. (1999). Making the body beautiful. A cultural history of aesthetic surgery. Princeton, NY, EE. UU.: Princeton University Press.

Goffman, E. (1991). La Ritualización de la Femineidad. En E. Goffman y Y. Winkin (Eds.), Los momentos y sus hombres (pp. 135-168). Barcelona, España: Paidós.

Goffman, E. (2006). Estigma. La identidad deteriorada. Buenos Aires, Argentina: Amorrortu. (Trabajo original publicado en 1964).

Gooren, J. L. (2000). Tratamiento Hormonal para la Reasignación de Sexo. BSTc. Sexualidad, ciencia y política, (4), 4-7.

Haraway, D. (1995). Ciencia, cyborgs y mujeres. La reinvención de la naturaleza. Madrid, España: Cátedra.

Kessler, S. y McKenna, W. (1978). Gender. An ethnomethodological approach [Género. Un enfoque etnometodológico].. NY, EE. UU.: John Wiley \& Sons.

Klein, R. (1996). (Dead) Bodies Floating in Cyberspace: Post-modernism and the Dismemberment of Women. In D. Bell and R. Klein (Eds.), Radically Speaking (pp. 346-358). Melbourne, USA: Spinifex.

Laqueur, T. (1994). La construcción del sexo desde los griegos hasta Freud. Madrid, España: Cátedra.

Le Breton, D. (2002). Las pasiones ordinarias (1a. ed.). Buenos Aires, Argentina: Editorial Nueva Visión.

Le Breton, D. (2007a). El sabor del mundo-Una antropología de los sentidos (1a. ed). Buenos Aires, Argentina: Editorial Nueva Visión.

Le Breton, D. (2007b). Adiós al cuerpo (O. Flores Flores, Trad.). México: La Cifra Número. 
Le Breton, D. (2008a). Antropología del cuerpo y modernidad. Buenos Aires, Argentina: Nueva Visión.

Le Breton, D. (2008b). La sociología del cuerpo. Buenos Aires, Argentina: Nueva Visión.

Mauss, M. (1979). Técnicas y Movimientos Corporales. En Sociología y Antropología (pp. 337-356). Madrid, España:Tecnos.

Mead, M. (1979). Sexo y temperamento en tres sociedades primitivas. Barcelona, España: Paidós.

Mejía, N. (2006). Transgenerismos. Una experiencia transexual desde la perspectiva antropológica. Barcelona, España: Bellaterra.

Merleau-Ponty, M. (1975a). Fenomenología de la percepción. México: Fondo de Cultura Económica.

Merleau-Ponty, M. (1975b). Reflexión sobre la antropología fenomenológica. Sao Paulo, Brasil: Abril.

Moore, H. (1994). Las Divisiones en: Sexo, Género y Diferencia Sexual. En La pasión por la diferencia (pp. 8-27). Madrid, España: Cátedra.

Nieto, J. A. (1998). Transgénero/Transexualidad: de la crisis a la Reafirmación del deseo. En J. A. Nieto (Ed.), Transexualidad, transgenerismo y cultura. Antropología, identidad y género (pp. 11-37). Madrid, España: Talasa.

Núñez, E. (2003a). La Transexualidad en el Sistema de Géneros Contemporáneo: del Problema de Género a la Solución de Mercado. En R. Osborne y Ó. Guash (Eds.), Sociología de la sexualidad. Madrid. España: Siglo XXI.

Osborne, R.y Guasch, Ó. (2003b). Sobre Diversidad Sexual: de Homos, Heteros, Transs, Queer. En R. Osborne y Ó. Guash (Eds.), Sociología de la sexualidad (pp. 99-125). Madrid. España: Siglo XXI. 
Plaza, M. (2007). Sobre el Concepto de'Violencia de Género'. Violencia Simbólica, Lenguaje, Representación. Extravío, 2. Recuperado de http://www. uv.es/extravio/extravio_web.html

Psikoeduca. (2008, 23 de marzo). Construcción social-Sistema de género. Blog sobre perspectiva de género. Recuperado de http://educapsico.wordpress.com/2008/03/23/construccion-social-sistema-degenero/\#comments

Reischer, E. y Koo, K. (2004). El Cuerpo Hermoso Organismo del Mundo Social y Simbolismo. Informe anual de antropología, (33), 297-317.

Sahlins, M. (1982). Uso y abuso de la biología: una crítica antropológica de la sociobiología. Madrid, España: Siglo XXI.

Sahlins, M. (1988). Cultura y razón práctica. España: Gedisa.

Soley, P. (2001). Transexualismo y la matriz heterosexual: un estudio crítico y empírico de preformativas teoría Judith Butler de género. Disertación doctoral no publicada, Unidad de Estudios de Ciencias, Universidad de Edimburgo, Escocia.

Stolcke, V. (2000). ¿Es el Sexo para el Género lo que la Raza para la Etnicidad... y la Naturaleza para la Sociedad? Política y Cultura, (14), 25-60.

Stolcke, V. (2003). La Mujer es Puro Cuento: la Cultura del Género. Cuadernos del Instituto Catalán de Antropología, (19), 69-95.

Turner, B. (1989). El cuerpo y la sociedad. Exploraciones en teoría social. México: Fondo de Cultura Económica.

Vartabedian, J. (2007). El Cuerpo como Espejo de las Construcciones de Género. Una Aproximación a la Transexualidad Femenina. Universitat de Barcelona. Recuperado de www.raco.cat/index.php/QuadernselCA/article/ viewFile/109038/136554

Wilson, E. O. (1980). Sociobiología: la nueva síntesis. España: Omega. 